\title{
DENTAL CERAMICS AND THE MOLAR CROWN TESTING GROUND
}

\author{
Van P. THOMPSON \\ Department of Biomaterials and Biomimetics, New York University College of Dentistry. \\ Dianne E. REKOW \\ Division of Basic Sciences, New York University College of Dentistry.
}

\begin{abstract}
$A$ 11 ceramic crowns are highly esthetic restorations and their popularity has risen with the demand for life-like and cosmetic dentistry. Recent ceramic research has concentrated on developing a fundamental understanding of ceramic damage modes as influenced by microstructure. Dental investigations have elucidated three damage modes for ceramic layers in the $0.5-2 \mathrm{~mm}$ thickness using point contacts that duplicate tooth cuspal radii; classic Hertzian cone cracking, yield (pseudo-plastic behavior), and flexural cracking. Constitutive equations based upon materials properties have been developed that predict the damage modes operational for a given ceramic and thickness. Ceramic thickness or thickness of the stiff supporting core in layer crowns is critical in flexural cracking as well as the flaw state of the inner aspect of the crown. The elastic module of the supporting structure and of the luting cement and its thickness play a role in flexural fracture. Clinical studies of ceramics extending over 16 years are compared to the above relationships and predictions. Recommendations for clinical practice are made based upon the above.
\end{abstract}

UNITERMS: Ceramics; Flexural fatigue; Radial fracture; Quasi-plasticity; Elastic modulus.

\section{INTRODUCTION}

All-ceramic crowns are appealing because of their enhanced esthetics, biocompability and inertness. The full potential of these restorations has not been realized because of relatively high failure rates in high stress applications such as molar crowns or for posterior bridges. Our ceramics research team from New York University College of Dentistry, the Materials Design and Research Laboratory of the US National Institute of Technology, the Department of Mechanical Engineering at the University of Maryland, the Department of Mechanical and Aerospace Engineering at Princeton University, and the Department of Prosthodontics at the University of Medicine and Dentistry of New Jersey has over the last 7 years participated in a research program on all-ceramic crowns. The major focus is to elucidate the damage modes and fatigue mechanisms operating in all-ceramic full crowns. The long term objective is to derive a design specification for new materials that can be successful as molar crowns fabricate with CAD/CAM techniques. Molar crowns are the focus as they represent the greatest design challenge where high loads and high numbers of cyclic contacts are operational. This paper will review briefly the current clinical research on all-ceramic molar crowns and then explore our understanding of the damage modes and fatigue mechanisms contributing to clinical failures. Finally, emerging guidelines for crown design will be discussed, focusing on the need for additional research on the interplay between ceramic materials, luting cements and remaining tooth structure.

Ceramics for crowns can be generally classified into 3 general categories; glasses, glass-ceramics and structural ceramics. Feldspathic glasses are the principal materials for veneering of metals and for glassceramics and for structural ceramics. Generally, they are high leucite glasses such as IPS Empress (Ivoclar, Schaan, Lichtenstein) and Optec (Pentron, Wallingford, CN, USA), Finesse (Dentsply/Ceramco Lakewood, NJ, USA), The latter is typical of the new low fusing porcelains having additional network modifiers and fine grained leucite inclusions. (The finer inclusions help to increase the fracture toughness of these porcelains.) All of these porcelains are available in pressable form and are used for lost wax technique crown fabrication. The feldspathic porcelains have not been extensively utilized for molar crowns but considerable experience exist in there usage for monolithic crowns on maxillary 
incisors where forces are limited.

Clinical experience with high leucite feldspathic molar crowns (Empress) has been disappointing with failure rates of $30 \%$ at a mean age of 8.7 years, in a small clinical study ${ }^{12,13}$. Recently, in a much larger study the results are more far more encouraging ${ }^{40}$ and unexplained when compared with other ceramics. As will be discussed later, feldspathic porcelains have low flexural strength and low fracture toughness, but are relatively fatigue resistant ${ }^{21}$. This may help explain there excellent clinical longevity when utilized for veneering metal $^{58}$. Another high leucite porcelain, Optec, had high failure rates $(\sim 25 \%)$ at 5 years ${ }^{17}$.

Some years ago the pressable glass-ceramic, Dicor (Caulk/Dentsply, Milford, DE, USA) was introduced. It had a higher strength than conventional porcelain, an elastic modulus similar to enamel and good esthetics. Its usage was extended to molar restorations and CAD/ CAM formulations were also introduced. Clinical studies of this monolithic material indicted good initial success, but over longer periods of time failure rates approaching 5\% per year on molar crowns have been reported $^{37,53}$. Another high strength glass-ceramic has been developed and utilized as a core for layered crowns is Empress II (Ivoclar, Schaan, Litchenstein). This glass matrix core material has needles of ceramic, a lithium disilicate glass, as the dispersed phase. Long term clinic studies on failure rates for layered molar crowns fabricated from this system have not yet been published.

High failure rates for molar crowns and the potential to extend all-ceramic restorations to fixed prostheses has lead to consideration of structural ceramics as core substructure for crowns. The first to have a major impact in dentistry is comprised of a partial sintered alumina core that is infiltrated with a glass at high temperature. This core is then veneered with porcelain adjusted to have the correct coefficient of thermal expansion. The resulting restoration (In-Ceram, Vita Zahnfabrik, Bad Säkingen, Gernany) has been used extensively for a number of years with excellent short term success rates ${ }^{52}$, while failure rates for molar crowns are reported as 1-2\% per year over 5 years ${ }^{44}$. $\mathrm{CAD} / \mathrm{CAM}$ is now utilized for In-Ceram cores and the failure rate is reported as below $1 \%$ per year $^{5}$. In a long term study involving over 200 molar crowns the failure rate has accelerated and the failure rate is now $3.5 \%$ per year average over 10 years. This may indicate a build up of damage leading to failure with time.

Another structural ceramic layer crown, is comprised of a spray cast and densified alumina core which is then hand veneered with feldspathic porcelain
(Procera, Nobelbiocare, Göthborg, Sweden). The first clinical study that extended for 5 years found a molar failure rate of $1.2 \%$ per year ${ }^{45}$. Procera crowns are highly popular in the United States but recently the very high strength structural ceramic yittria stabilized zirconia (YTZP) has been introduced as competition. Both systems involve CAD/CAM of partially sintered YTZP which is shaped and then fired to full density (Cercon, Ceramco Dentsply, Lakewood, NJ, USA and LAVA, 3MEspe, Seefeld, Germany). There are no molar crown clinical studies of sufficient longevity to determine the success of the zirconia core crowns.

The question remains as to how, why and when allceramic crowns fail and how this relates to the materials employed as well as their configuration. The complexity of the situation becomes apparent with review of the failure modes, crown design, cementation media, loading conditions and directions, supporting tooth structure (natural dentin, build-up, or post and core) and the harsh environment.

\section{Failure and Damage Modes}

The glasses, glass-ceramic and structural core ceramics have widely varying strengths, elastic moduli and fracture toughness (Table 1) yet failure rates over long term do not necessary correspond with these variables but may be more directly relate to fatigue behavior. Using a blunt contact indentor (Hertzian contact) that simulates the general geometry of an opposing cusp on a ceramic (Figure 1) it was found that repeated contact over many cycles can lead to a sharp lowering of the strength of a ceramic over time (Figure 2) $)^{21,49}$ indicating an accumulation of damage beneath the indentor (cracks propagate through the indentation area). This lead to questions as to how crowns fail as well as to how ceramics of varying thickness respond to Hertzian contacts.

All-ceramic crowns are often replaced because of bulk fracture, a catastrophic failure mode noted for both monolithic (e.g., Dicor) and layered crowns $^{25,26,27,54}$. This fracture initiates from the inner surface of the ceramic (the cementation surface) where tensile strength is highest, then propagates through the material to outer surface, ultimately leading to fracture ${ }^{23,24}$.

Three types of damage mechanisms are possible for a ceramic plate supported by a lower stiffness material such as dentin depending upon the thickness of the ceramic and the layers involved (Figure 3$)^{43}$. The constitutive equations governing this failure mode are also presented and indicate the load at which the cracking of the various types or yield is initiated. Hence 
TABLE 1- Characteristics of some ceramic-based materials

\begin{tabular}{|c|c|c|c|c|c|c|}
\hline Material & $\begin{array}{l}\text { Product } \\
\text { Name }\end{array}$ & $\begin{array}{l}\text { Modulus } \\
\mathrm{E}(\mathrm{GPa})\end{array}$ & $\begin{array}{l}\text { Hardness } \\
\text { H(GPa) }\end{array}$ & $\begin{array}{l}\text { Toughness }^{b} \\
\text { T }\left(\text { MPa. }^{1 / 2}\right)\end{array}$ & $\begin{array}{l}\text { Strength } \\
\mathrm{F}_{\mathrm{F}}(\mathrm{MPa})\end{array}$ & Supplier \\
\hline \multicolumn{7}{|l|}{ Veneer Ceramics } \\
\hline Porcelain & Mark II & 68 & 6.4 & 0.92 & 130 & Vita Zahnfabrik \\
\hline \multicolumn{7}{|l|}{ Monolithic Ceramics } \\
\hline Glass Ceramic & Dicor & & & & $114-120$ & Denstply Caulk \\
\hline \multicolumn{7}{|l|}{ Core Ceramics } \\
\hline Porcelain & Empress & & & & & Ivoclar \\
\hline Glass Ceramic & Empress II & & & & & Ivoclar \\
\hline Alumina (infiltrated) & InCeram & 270 & 12.3 & 3.0 & 500 & Vita Zahnfabrik \\
\hline Alumina (slip cast) & Procera & & & & $600-687$ & Nobel BioCare \\
\hline \multicolumn{7}{|l|}{ Zirconia Glass } \\
\hline infiltrated & InCeram Zirconia & 245 & 13.1 & 3.5 & 245 & Vita Zahnfabrik \\
\hline \multirow[t]{2}{*}{ Zirconia (Y-TZP) } & Prozyr & 205 & 12.0 & 5.4 & 1450 & Norton \\
\hline & & & & & & Desmarquest \\
\hline \multicolumn{7}{|c|}{ Experimental model materials } \\
\hline Polycarbonate & Hyzon & 2.3 & & 0.15 & & AIN Plastic \\
\hline Epoxy & RT Cure & 3.5 & & & & Master Bond \\
\hline Glass & Soda-lime & 73 & 5.2 & 0.67 & 110 & Fisher Scientific \\
\hline Tooth contact & Tungsten Carbide & 614 & 19.0 & & & \\
\hline \multicolumn{7}{|l|}{ Tooth } \\
\hline Enamel & & $70-80$ & & $0.6-0.9$ & & \\
\hline Dentin & & & & & & \\
\hline
\end{tabular}

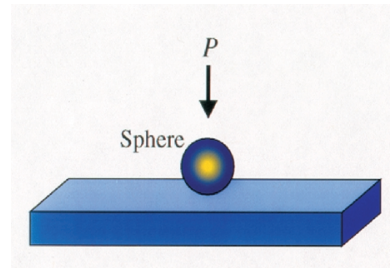

Hertzian indentation

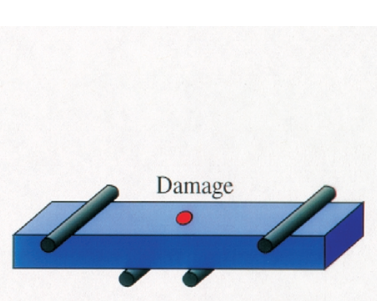

Four point bending test
- Indentation load, $P$

- Number of cycles, $n$

Environment (dry, air, water)

FIGURE 1- Schematic of Hertzian contact fatigue testing of ceramic flexural test bars. Following contact testing ceramic is subject to 4 -point bending at $0.5 \mathrm{~mm}$ per minute the type of response to loading can be predicted from knowledge of toughness, hardness, elastic modulus and flexural strength of the ceramic and supporting structures along with the radius of the indenter.

When the ceramic is thick "bulk properties" dominate, designated as "monolith, thick coating" in the upper portion of the figure. Here glass cone cracking is observed and behavior is typically noted for dental porcelains and fine grained glass ceramics ${ }^{48}$. This behavior is independent of the substrate supporting the ceramic and is responsible for chipping and surface cracks in porcelain inlays and onlays as well as for veneering porcelains. Alternatively, in coarse grained glass ceramics and in structural ceramics such as glassinfiltrated ceramics, alumina and zirconia quasi-plastic 


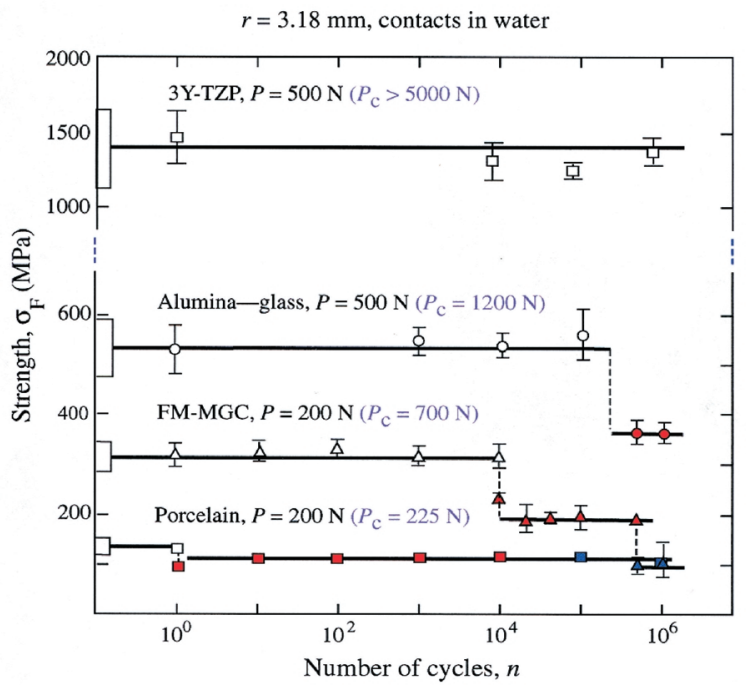

FIGURE 2- Summary of Hertzian contact fatigue testing of various ceramics. Following Hertzian contact of a WC sphere at the indicated load for a given number of cycles of flexural strength was determined with 4-point loading. The change in symbol indicates a change in the failure mode. Note the change in scale on the load axis

\begin{tabular}{|c|c|c|}
\hline $\begin{array}{l}\text { Monolith, } \\
\text { thick coating }\end{array}$ & c & $\begin{array}{l}\text { Cone crack } \\
P_{\mathrm{C}}=A\left(T_{\mathrm{c}}^{2} / E_{\mathrm{c}}\right) r\end{array}$ \\
\hline & c & $\begin{array}{c}\text { Yield } \\
P_{\mathrm{Y}}=D H_{\mathrm{c}}\left(H_{\mathrm{c}} / E_{\mathrm{c}}\right)^{2} r^{2}\end{array}$ \\
\hline Bilayer & $\mathrm{c}$ & $\begin{array}{c}\text { Radial crack } \\
\left.P_{\mathrm{R}}=B S_{\mathrm{c}} d^{2} / \log \left(E_{\mathrm{c}} / E_{\mathrm{s}}\right), \quad \text { (fast }\right) \\
P_{\mathrm{R}}=C / t^{1 / N}, \text { (slow) }\end{array}$ \\
\hline Trilayer & \begin{tabular}{|l}
$\mathrm{o}$ \\
$\mathrm{i}$ \\
\end{tabular} & $\begin{array}{c}\text { Radial crack } \\
P_{\mathrm{R}}=B S_{\mathrm{i}} d^{2} /\left[\left(E_{\mathrm{i}} / E_{k}\right) \log \left(E_{*} / E_{\mathrm{s}}\right)\right]\end{array}$ \\
\hline
\end{tabular}

FIGURE 3- Schematic of ceramic layers c (bilayers), $o$ and i (trilayers) on compliant substrates s. Common damage modes from occlusal-like contacts indicated: surface cone cracks and quasiplastic yield zone at top surface; flexural radial cracks at ceramic bottom surfaces. Corresponding analytical relations for critical loads given, in terms of key variables: contact test-load $P$, test duration $t$, geometriclayer thickness $d$, sphere radius $r$ : materials, Young's modulus $E$, hardness $H$, strength $S$, toughness $T$, crack velocity exponent $N$. Quantities $A, B, C$ and $D$ are coefficients yield can occur beneath the indenter 22,49 . The quasiplastic damage develops in a zone beneath the surface and is believed to be caused by slippage between grain boundaries in structural ceramics.

When the thickness of the ceramic falls below about $1 \mathrm{~mm}$ flexural radial cracking becomes predominate and the failure load is independent of the radius of the indenter (shown as a "bilayer" in Figure 3). The stiffness of the substrate (e.g., luting cement and tooth structure) plays a role in the load to cause failure as noted in the slowly changing logarithmic term $\left(\mathrm{E}_{\mathrm{c}} / \mathrm{E}_{\mathrm{s}}\right)$ term. The dominate terms are the $\mathrm{d}^{2}$ dependence on thickness and secondarily the flexural strength of the ceramic, S. This relationship holds over the entire spectrum of glasses, glass-ceramics and structural ceramics utilized in dentistry (Figure 4) ${ }^{30,32}$. Monolithic crowns from materials such as Dicor or Empress are anticipated to fail by this mechanism if thin areas are subjected to cyclic loading above some threshold where damage can accumulate as will be discussed below.

A "trilayer" structure is characterized in Figure 3 as a low modulus veneering porcelain on a stiff glassceramic or structural ceramic crown core supported by a substrate (again luting cement and tooth structure). This represents an Empress II, In-Ceram, Procera, Cercon, or LAVA crown. Once again $\mathrm{d}^{2}$ is the

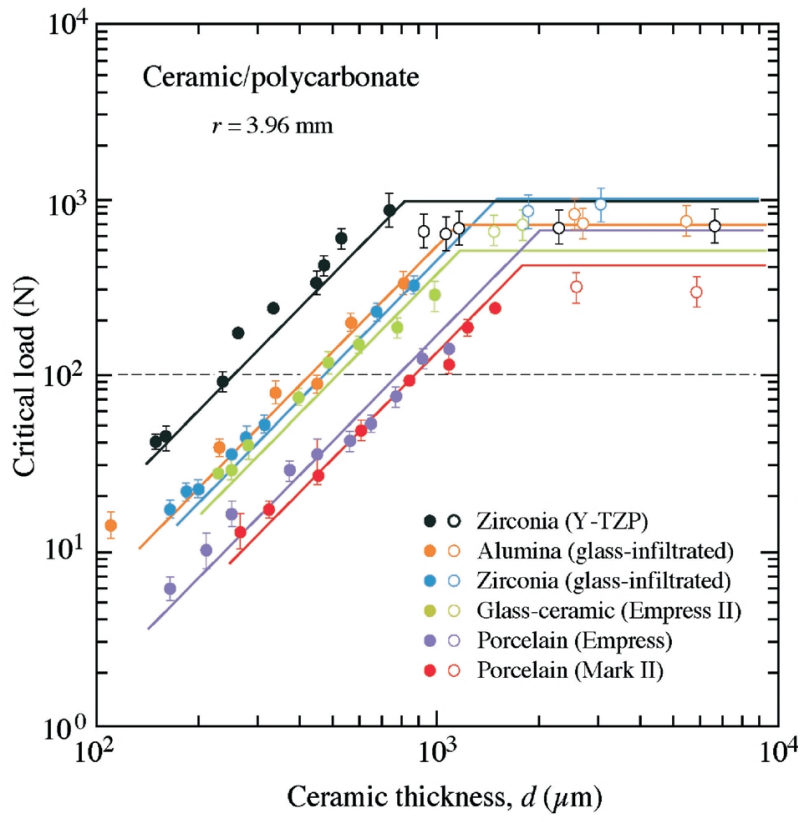

FIGURE 4- Critical loads $P$ for first damage in ceramic/ polycarbonate bilayers as function of ceramic thickness $d$, for indentation with WC sphere $(r=4 \mathrm{~mm})$, for a range of dental ceramics. ${ }^{18}$ Symbols are experimental data (standard deviation bounds). Solid lines are theoretical predictions for cone cracking and quasiplasticity (horizontal lines) and radial cracking (inclined lines) 
dominate term but is highly modified by the terms expressing the effective modulus of the combination of the outer veneering porcelain and its thickness relative to that of the stiff supporting ceramic core. The stiff structural supporting core carries the majority of the load and its thickness plays a critical role above a minimum thickness ${ }^{10}$ (Figure 5). Surprisingly, above this minimum thickness there is little change in load required to cause radial fracture as the thickness of the stiff core is increased and the veneer porcelain is thinned (total thickness is held constant at $1.5 \mathrm{~mm}$ ). Hence for a zirconia layered crown, increasing the zirconia core thickness from $0.4 \mathrm{~mm}$ to $1.0 \mathrm{~mm}$ does not cause a major change in strength and this holds across the range of stiff ceramics cores including the glass-ceramic (Empress 2) and glass infiltrated alumina (In-Ceram) and alumina (Procera).

Ceramics are also susceptible to surface flaws and cracking introduced during fabrication ${ }^{29}$ which could include machining damage from CAD/CAM procedures, alumina particle abrasion to remove investment or during bonding procedures or from "fit adjustment" diamond bur cutting. Using controlled Vickers indention to create surface flaws the reduction in load for initiation of radial fracture exhibits a significant reduction in strength for YTZP and glassinfiltrated alumina. The vertical lines in Figure 6 are placed to indicate the range of flaws estimated to result from $50 \mu \mathrm{m}$ alumina particle abrasion of these ceramics. The critical nature of damage to the inner surface of the all-ceramic crown becomes apparent even for procedures the dentist is taught to routinely apply to crowns to be bonded to tooth structure.

Additionally, most ceramics suffer from "slow crack" growth. When loaded over long periods of time moisture attacks the crack tip where the local molecular structure is strained. This leads to crack propagation at normal atmospheric conditions that is accelerated in water. Cyclic loading propagates cracks in a similar manner when the crack tip is stressed to a similar load. Using $1 \mathrm{~mm}$ thick ceramic layers bonded to polycarbonate (to simulate dentin) the load and duration of this load to cause flexural radial fracture is indicated (Figure 7). The calculation of this $\mathrm{P}_{\mathrm{r}}$ for slow crack growth in "bilayers' is given Figure 3 where the exponent $\mathrm{N}$ is the crack velocity and $\mathrm{C}$ is a dimensionless constant. The lines in Figure 7 are extended to predict the lowering of the load to cause flexural radial cracking at 1 or 10 years. Note that all of the ceramics tested are susceptible to slow crack growth, lowering the useful strength by $20-50 \%$ over 10 years depending upon the time at load. The time at load depends highly upon the patient and their habit patterns as to load and numbers of cycles.

\section{Relationship to Clinical Practice and Clinical Findings}

Performance of full coverage all-ceramic crown is determined by a complex combination of factors including the material selected, thickness, damage introduced during shaping and placement procedures, adhesive/luting system used, the tooth substrate (natural dentin or foundation restoration), and the fatigue response to complex loading of normal occlusal function. Competing failure mechanisms exist (Figures 3 and 4). For thin sections, radial fracture predominates. For thick specimens, cone cracks or quasi-plastic yield occurs first. The intersection of load to initiation of fracture between the types of failures depends upon the particular material. For all the materials investigated, the transition from fracture at the flexural inner surface to outer surface (where fractures are bulk-property driven) occurs within clinically relevant thickness (between approximately $1.0 \mathrm{~mm}$ for porcelains and $1.5 \mathrm{~mm}$ for zirconia (YTZP). Thus, it is not surprising that radial fractures are the prevalent fracture mode requiring crown replacement.

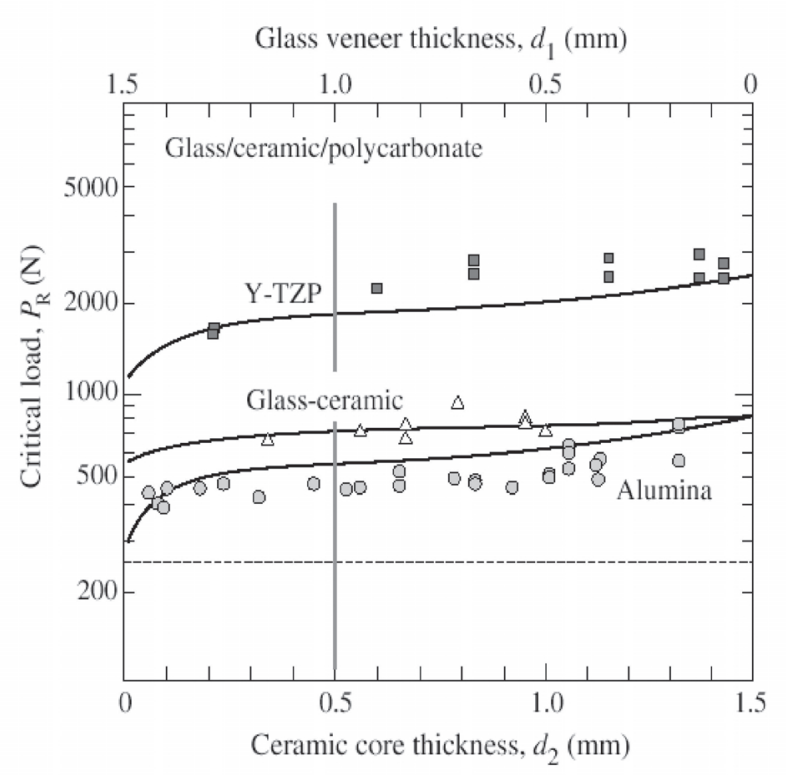

FIGURE 5- Critical loads $P_{\mathrm{R}}$ for inner core radial cracking as function of outer veneer thickness $d_{0}$ (or inner thickness $d_{i}$ ), for trilayers with common soda-lime glass outer layers and indicated inner core ceramic layers. Results for fixed net thickness $d=d_{0}+d_{i}=1.5 \mathrm{~mm}$. Data points are experimental data, solid curves are theoretical predictions. Vertical bars represents standard $0.5 \mathrm{~mm}$ thick structural ceramic core strength 
Minor changes in thickness can significantly impact the load at which onset of flexural radial fracture $\left(\mathrm{P}_{\mathrm{R}}\right)$ occurs since $P_{R}$ is proportional to the square of the thickness. The currently recommended thickness of $1.5 \mathrm{~mm}$ occlusal reduction ${ }^{51,55}$ is clearly needed for materials to withstand typical $100-200 \mathrm{~N}$ occlusal loads. Occlusal forces have been measured at substantially greater levels $\left(216-890 \mathrm{~N}^{16,17,19,41}\right)$, suggesting that greater thickness may be desired for a built-in "factor of safety".

$\mathrm{P}_{\mathrm{R}}$ is less sensitive to changes in material properties than to changes in thickness $\left(\mathrm{P}_{\mathrm{R}}\right.$ is proportional to the flexural strength $\left(\mathrm{S}_{\mathrm{c}}\right.$ or $\mathrm{S}_{\mathrm{i}}$ in Fig 3) and to the more slowly changing term of $\left.1 / \log \left(\mathrm{E}_{\mathrm{c}} / \mathrm{E}_{\mathrm{s}}\right)\right)$. Stronger materials, however, will raise the load required to initiate radial fractures. Flexural strength $\left(\mathrm{S}_{\mathrm{c}}\right.$ or $\left.\mathrm{S}_{\mathrm{i}}\right)$ is also dependent upon the flaws within the material ${ }^{33}$ as well as on the condition of the surfaces of the material; damaged surfaces reduce the strength ${ }^{9,15,33,42}$. This will be discussed below.

Surprisingly, $P_{R}$ is influenced less by the relative moduli of the layers than either the thickness or the initial strength of the ceramics $\left(\mathrm{P}_{\mathrm{R}}\right.$ is proportional to1/ $\log \left(\mathrm{E}_{\mathrm{c}} / \mathrm{E}_{\mathrm{s}}\right.$ where $\mathrm{E}_{\mathrm{s}}$ is the modulus of the supporting substrate). While not necessarily a major factor in determining $\mathrm{P}_{\mathrm{R}}$, this factor may account for differences in clinical performance of all-ceramic crowns on dentin $\left(\mathrm{E}_{\mathrm{s}}=20 \pm 2 \mathrm{GPa}^{59}\right)$, composite buildups $\left(\mathrm{E}_{\mathrm{s}}\right.$ approximately 15-20 GPa), or ceramic or metal post and cores ( $\mathrm{E}_{\mathrm{s}}$ approximately 200-300 GPa ${ }^{39,56}$. Further discussion of this aspect will explored below.

When glass-veneered ceramics cores are supported by a composite substrate (Figure 5), $\mathrm{P}_{\mathrm{R}}$ drops as a thicker veneer is added (moving from the right to the left of the figure). $P_{R}$ drops dramatically when the core thickness becomes less than $0.25 \mathrm{~mm}$ (the glass veneer thickness reaches approximately $1.25 \mathrm{~mm}$ ). The fundamentals of this behavior are not yet fully understood but affirm the clinical practice of not fabricating extremely thin cores with a thick veneering porcelain. Increasing the core thickness above 0.5 $\mathrm{mm}$, while the total core-veneer thickness is constant, has little influence on strength. In the intermediate thickness regions, strength is relatively insensitive to the changes in core (or veneer) thickness. This suggests an inbuilt tolerance to relative layer thickness in regions where the veneer/core flexing coating is under relatively little strain, much like an I-beam provides almost as much load-bearing capacity as a solid beam of the same dimensions $)^{33,34}$. The relative core-veneer thickness can be dictated by clinical demands for esthetics and/or fabrication technologies.

Hence, despite the fact that materials with greater strength are being introduced, the above analysis suggests that radial fractures will likely be the prevailing mode of clinical failure for the future. The challenge is that these fractures begin, undetected, at the internal surface of the crown and there is no way to detect their existence before they propagate and lead to catastrophic clinical failure ${ }^{30}$.

The fundamental relations presented in Figures 37 are based on performance of ceramics in flat layers with a single load applied in a dry environment. As such, they facilitate predictions of critical loads for ceramic crown systems in the best of all circumstances. Actual clinical performance is far more complex, with more layers to consider (veneer, core, cement which may include voids and variable thickness, and supporting tooth structure of dentin or foundation restoration), subjected to multiple complex loading cycles in a wet environment. Fatigue causes cumulative strength degradation in a variety of both core and veneering ceramics $4,6,8,11,21,31,46,47,49$ as well as in crowns $^{8}$ and is exacerbated in wet environments ${ }^{14}$. The complex geometry of the crown may influence the distribution of stresses ${ }^{1,2,7,20}$ and thereby the load at which on-set of fracture begins. The relationships discussed here represent the best case situation. With the other factors of clinical reality, the load to initiation of fracture will necessarily decrease.

Hence, all-ceramic crowns failure by bulk fracture and a typical facture patterns are shown in Figure 8. The failure extends through the core exposing the underlying tooth structure. Given the above results of

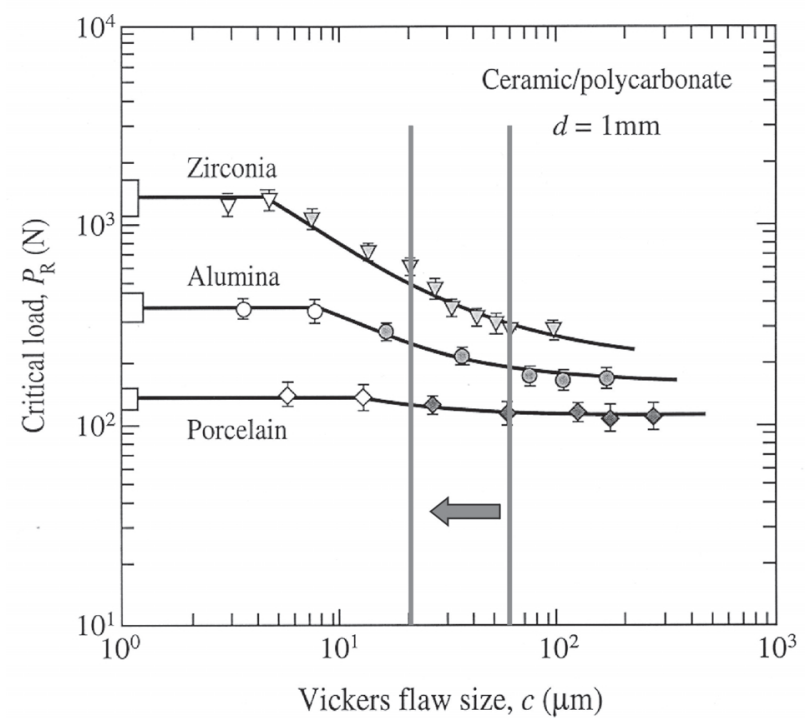

FIGURE 6- Critical load for flexural radial cracking, $P_{\mathrm{R}}$ for ceramic layers with inner surface flaws from Vickers indentations at specified loads. The vertical bars indicate the range estimated for flaws created with $50 \mu \mathrm{m}$ alumina particle abrasion of these ceramics 
studies on model ceramic layer structure is there clinical evidence that these relationships are operational and how should the above be used to guide clinicians in design of molar all ceramic crowns?

Fortunately, Dr. Kenneth Malament, a practicing prosthodontist, and part-time faculty member of Tufts University has over the last 17 years maintained and extensive database on all-ceramic crowns of various types since the introduction for the glass-ceramic, Dicor. Since then he has added both In-Ceram and Empress to this database which now comprises over 4000 crowns. Recently his longer term data has been subjected to comprehensive analysis ${ }^{37,38,39}$. Further he has collaborated with the authors in sharing his database and latest results ${ }^{40}$.

While crown thickness is a critical factor identified in the laboratory characterization of ceramic layer structures $^{32}$ and discussed above, it does not appear to be directly related to failure rates in the Malament study $^{38}$. Crown thickness was measured at 6 points and there is no correlation between thickness at these points and failure rate. This has also been investigated only for molar crowns ${ }^{35}$ where crowns with at least one thickness less than $1 \mathrm{~mm}$ were compared with those with all thicknesses above $1 \mathrm{~mm}$. This was found for both Dicor and In-Ceram. The failure rates for Dicor on molar crowns averaged about $5 \%$ per year over 16 years while for In-Ceram it was about $3.5 \%$ over 10 years. It appears that as long as the overall thickness of the crowns are over $1 \mathrm{~mm}$ (which is true in this database) there is no relationship to longevity.

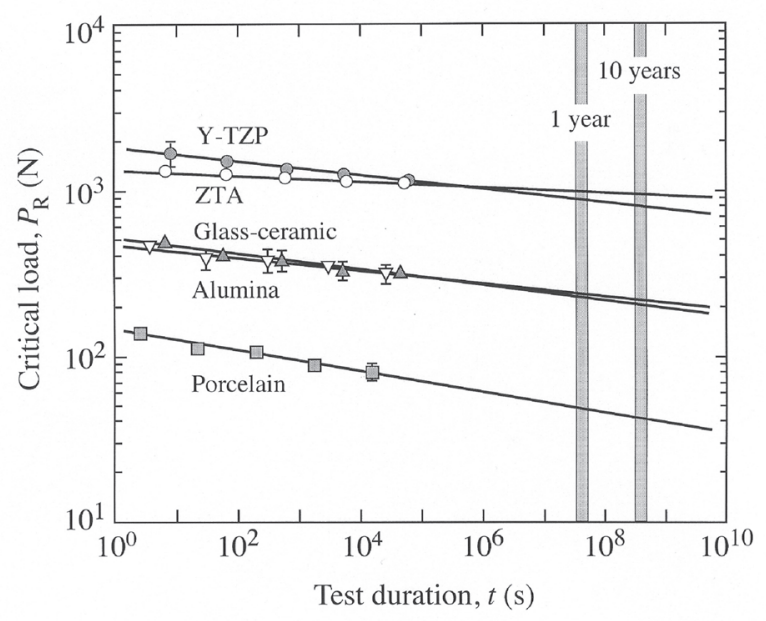

FIGURE 7- Critical loads $P_{\mathrm{R}}$ for radial cracking in ceramic/ polycarbonate bilayers as function of test duration $t$, for indentation with spheres. Data from constant loading rate tests. Slope of lines is a measure of susceptibility to slow crack growth. Critical loads diminish by a factor or two or more over about a year|
Another factor related to the crown and the flexural radial fracture mode is the support offered by the remaining tooth structure. According to the constitutive equations in Fig 3 the higher the elastic modulus of the supporting core the higher the load to failure. Use of a cast metal core or placement of a ceramic core would provided a high modulus support as compared to dentin. The Malament study indicates that with gold or ceramic tooth build up the longevity of either Dicor or In-Ceram is doubled ${ }^{35,36,39}$, Another finding from analysis of this database for molar crowns was that the failure incidence for crowns luted with glass ionomer cement (Ketac-cem, ESPE, Seefeld, Germany) was equivalent to those "bonded" with resin cement (Dicor Adhesive Cement. Caulk Dentsply, Milford, DE, USA). There is insufficient data to compare dentin structure to high modulus tooth build-up materials with these two cements. However, the higher modulus glass-ionomer cement was equivalent to the resin cement on dentin supported Dicor crowns.

As noted above a further factor in the support offered by the tooth substrate system to the ceramic

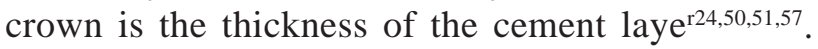
The cement is of low elastic modulus $(2-10 \mathrm{GPa})$ as compared to dentin (15-20 GPa). Increasing the thickness of the cement can have a large effect on reducing flexural failure load. The results of a study on the load to failure of silicon (high elastic modulus) bonded to glass (moderate elastic modulus) with variation in the thickness of the bonding epoxy layer

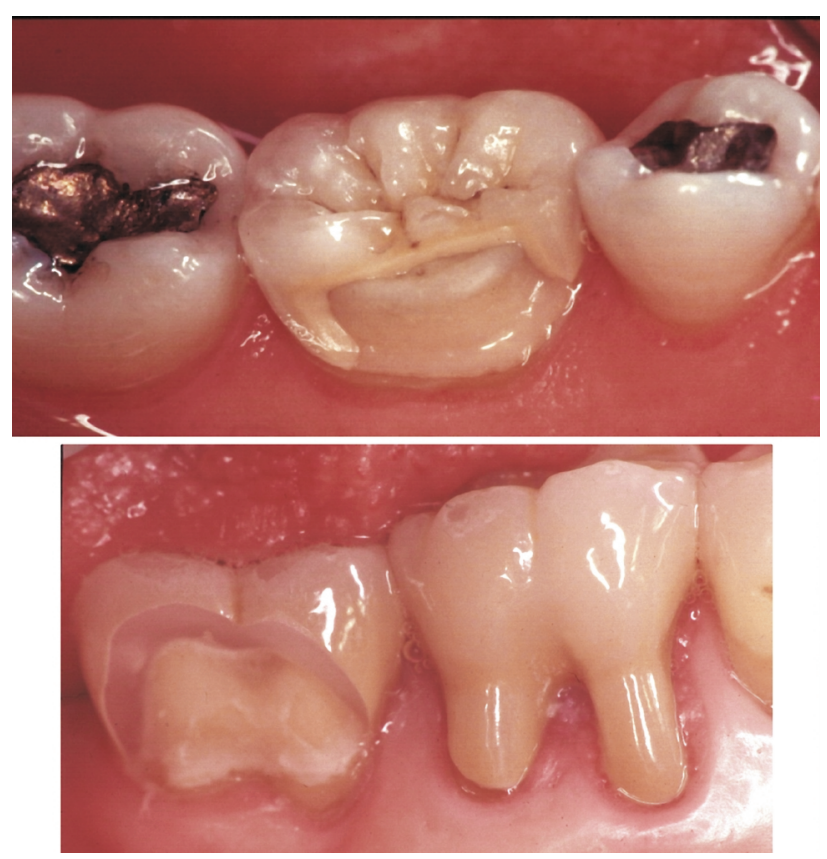

FIGURE 8- Examples of failed crowns: the upper is an InCeram crown while the lower is the monolithic ceramic, Dicor. (Courtesy of K. Malament) 
(low elastic modulus) indicates that increasing the thickness of this layer from 20 to $200 \mu \mathrm{m}$ cement dropped the relative strength by $50 \%$ (Figure 9$)^{28}$. This system is an analogue to a structural ceramic crown on dentin with variation in cement thickness. In the Malament study it now known that the dental laboratory fabricating the In-Ceram crowns employed heavy die spacing to achieve adequate fits to the dies as compared to the Dicor prepared crowns ${ }^{35}$. This general increase in cement thickness may help explain the accelerating failure rate for the In-Ceram crowns with length of service. Less support as a result of a thick cement layer coupled with slow crack growth is a possible scenario. Voids in cement can have negative influences ${ }^{3}$ increasing the above problem.

Another aspect of the Malament study is the comparison between Dicor crowns that were acid etched and those placed without etching. A more than doubling of the failure rate was noted for the latter ${ }^{37}$. This might be thought to be attributed to lack of adhesion between the cement and the crown. However, the equivalent results for the glass ionomer cements as compared to the resin cements for acid etched crowns would suggest that adhesion is not critical. A plausible alternative is related to surface preparation of the crown prior to acid etching. The Dicor crowns were each alumina particle abraded in the dental laboratory prior to cementation. Particle abrasion of this glassceramic has been shown to lower the strength by $30 \%$ or equivalent to 10,000 cycles of indentation loading at $200 \mathrm{~N}$ as in Figure 1049. Acid etching (Dicor Etchant, Caulk Dentsply, Milford, DE, US) of Dicor requires a specially formulated fluoride solution. It attacks the surface of the Dicor preferentially removing the glass

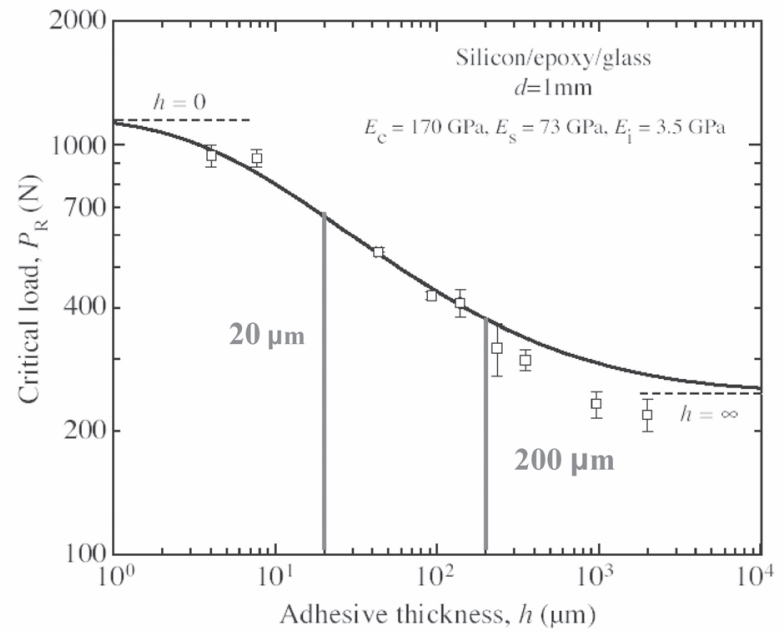

FIGURE 9- Critical load for flexural radial cracking, $P_{\mathrm{R}}$ for silicon epoxy bonded to glass with variation in the epoxy layer thickness. The curve is a theoretical fit matrix. The superior results found with acid etched Dicor crowns may be related to the removal of the surface flaws created by particle abrasion with etching of the glass. This would improve the strength as well as retard the initiation of slow crack growth. The finding discuss here strongly suggest that we consider alternative treatments for the cementation surface of ceramic crowns to reduce preparation and fitting damage rather than promotion of particle abrasion to improve bonding.

In summary, based upon the above studies radial fractures will remain the most problematic in dental restorations in future. The impact of minor changes in crown thickness below $1 \mathrm{~mm}$ will have a large impact on susceptibility to fracture and, therefore, clinical performance. Stronger materials will permit thinner crowns to be considered - but the prevailing failure mechanism will remain the troublesome flexural radial fractures that cannot be seen (and therefore cannot be repaired) until they cause catastrophic failure of the crown. The relationships describe above provide guidance for ranking anticipated performance of existing and future ceramic systems. Additionally, they provide guidance to the clinician regarding material selection when occlusal reduction is limited by physiological constraints.

\section{CONCLUSIONS}

Fundamental relationships for initiation of each the three mechanisms of failure (cone cracks, quasi-plastic damage, and radial cracks) resulting from occlusal contact in all-ceramic crowns have been discussed.

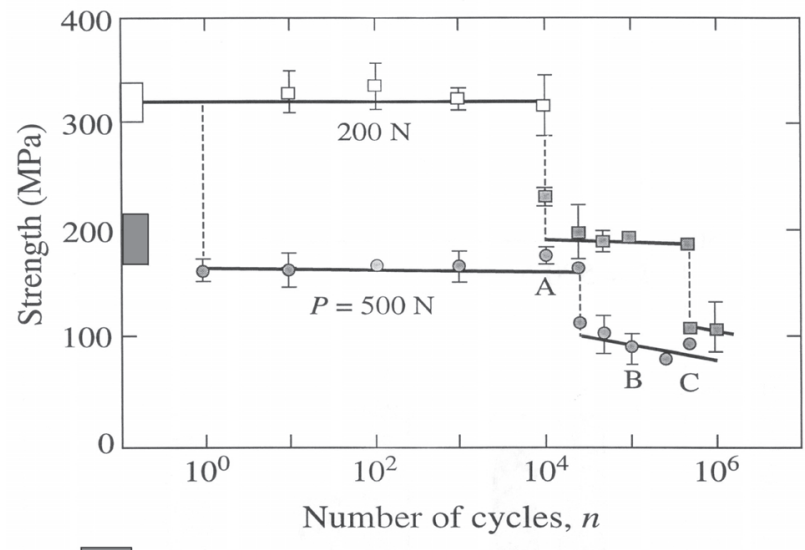

Strength range following $50 \mu \mathrm{m}$ alumina particle abrasion

FIGURE 10- Hertizian contact flexural fatigue strength the lass-ceramic, Dicor. Tested as shown in Figure 1. The red bar indicates the strength following $50 \mu \mathrm{m}$ alumina particle abrasion 
The role of the high elastic modulus crown core in supporting the load on the entire veneer-core structure has been reviewed. The influence of substrate modulus and cement thickness have been presented along clinical results validating it performance. The importance of limiting surface damage on the inner surface of the crown has been presented in light of both laboratory and clinical findings. The role of slow crack growth to potentially lower the effective strength of ceramics has been discussed. All of these factors and relationships apply across classes of materials used for crowns, including porcelains, glass-ceramics, and structural ceramics. Based on these factors and relationships:

(1)Flexural radial fracture, originating from the cementation surface of a crown, is and will remain the predominate failure mechanism for all-ceramic crowns despite the introduction of stronger materials. For a given ceramic, the load to initiation of a radial fracture $\left(\mathrm{P}_{\mathrm{R}}\right)$ is primarily influenced by crown thickness and, to a lesser extent, the relative elastic modulii between the crown and the supporting tooth substrate.

(2)For layered crowns (where a high elastic modulus core supports the majority of the occlusal load), increasing core thickness above $0.5 \mathrm{~mm}$, while maintaining the total veneer-core thickness constant $(1.5 \mathrm{~mm})$, does little to increase the strength of the crown.

(3) The role of the relative stiffness of the tooth substrate support is verified in clinic studies and points out the need to limit the thickness of the luting cement/ adhesive whenever possible.

(4) Particle abrasion of the crown cementation surface should be avoided as well as any modification to the inner surface of the crown prior to cementation

(5) Clinical findings suggest that bonding to the inner surface of the crown may not be necessary.

\section{REFERENCES}

1-Abu-Hassan MI, Abu-Hammad OA, Harrison A. Stress distribution associated with loaded ceramic onlay restorations with different designs of marginal preparation. An FEA study. J Oral Rehabil 2000; 27:294-8.

2-Anusavice, KJ, Hojjatie B. Influence of incisal length of ceramic and loading orientation on stress distribution in ceramic crowns. J Dent Res 1988; 67:1371-5.

3-Anusavice KJ, Hojjatie B. Tensile stress in glass-ceramic crowns: effect of flaws and cement voids. Int J Prosthod 1992; 5: 351-8.

4-Baran G, Boberick K, McCool J. Fatigue of restorative materials. Crit Rev Oral Biol Med 2001; 12:350-60.
5-Bindl A, Mormann W.H. An up to 5-year clinical evaluation of posterior in-ceram CAD/CAM core crowns. Int J Prosthodont 2002; 15:451-6.

6- Cai H, Kalceff MAS, Hooks BM, Lawn BR, Chyung K. Cyclic fatigue of a mica-containing glass-ceramic at Hertzian Contacts. J Mater Res 1994; 9:2654-61.

7-Cao Y. Stress and crack analysis of ceramic crowns in contact and characterization of material removal in machining of dental ceramics. Mechanical Engineering. College Park, University of Maryland, 2000.

8- Chen HY, Hickel R, Setcos JC, Kunzelmann KH. Effects of surface finish and fatigue testing on the fracture strength of CADCAM and pressed-ceramic crowns. J Prosthet Dent 1999; 82: 468-75.

9-Cook R F, Lawn BR, et al. Effect of machining damage on the strength of a glass ceramic. J Amer Ceram Soc 1981;64:121-2.

10-Deng Y, Lawn B, Lloyd IK. Damage characterization of dental materials in ceramic-based crown-like layer structures. Key Eng Mater 2002; 224-6:453-8.

11- Drummond JL, King TJ, Bapna MS, Koperski RD. Mechanical property evaluation of pressable restorative ceramics. Dent Mater 2000;16:226-33.

12-Fradeani M. Six-year follow-up with Empress veneers. Int J Periodontics Restorative Dent 1998;18:216-25.

13-Fradeani M, Redemagni M. An 11-year clinical evaluation of leucite-reinforced glass-ceramic crowns: a retrospective study. Quintessence Int 2002; 33:503-10.

14- Gladys S, Braem M, Van Meerbeek B, Lambrechts P, Vanherle $\mathrm{G}$. Immediate versus one-month wet storage fatigue of restorative materials. Biomaterials 1998; 19:541-4.

15-Griggs JA, Thompson JY, Anusavice K. Effects of flaw size and auto-glaze treatment on porcelain strength. J Dent Res 1996;75: 1414-7.

16- Hagberg C, Agerberg G, Hagberg M. Regression analysis of electromyographic activity of masticatory muscles versus bite force. Scand J Dent Res 1985; 93:396-402.

17-Hankinson J A, Cappetta EG. Five years clinical experience with a leucite-reinforced porcelain crown system. Int J Periodont Rest Dent 1994;14:138-53.

18- Helkimo E, Carlsson GE, Helkimo M. Bite force and state of dentition. Acta Odontol Scand 1977; 35:297-303.

19-Hellsing, E, Hagberg C. Changes in maximum bite force related to extension of the head. Eur J Orthod 1990; 12:148-53.

20-Hojjatie B, Anusavice KJ. Three-dimensional finite element analysis of glass-ceramic dental crowns. J Biomech 1990;23:115766.

21- Jung YG, Peterson IM, Kim DK, Lawn BR . Lifetime-limiting strength degradation from contact fatigue in dental ceramics. J Dent Res 2000 Feb; 79: 722-31. 
22- Jung YG, Peterson IM, Pajares A, Lawn BR. Contact damage resistance and strength degradation of glass-infiltrated alumina and spinel ceramics. J Dent Res 1999b Mar; 78: 804-14.

23-Kelly J, Hunter B. Simulating clinical failure during in vitro test of all-ceramic crowns[abstract 1175]. J Dent Res 77: 778.

24-Kelly JR. Clinically relevant approach to failure testing of allceramic restorations. J Prosthet Dent 1999; 81: 652-61.

25-Kelly JR, Campbell SD. Fracture-surface analysis of dental ceramics. J Prosthet Dent 1989; 62: 536-41.

26-Kelly JR, Giordano R, et al. Fracture surface analysis of dental ceramics: clinically failed restorations. Int J Prosthodont 1990; 3: 430-40.

27- Kelly JR, Tesk JA, Sorensen JA . Failure of all-ceramic fixed partial dentures in vitro and in vivo: analysis and modeling.J Dent Res 1995; 74:1253-8.

28-Kim JH, Miranda P, Kim DK, Lawn BR. Effect of an adhesive interlayer on the fracture of a brittle coating on a supporting substrate. J Mater Res 2003;8:222-7.

29-Kingery WD, Bowen HK. Introduction to ceramics. New York, John Wiley, 1976.

30- Lawn BR, Deng Y, Thompson VP. Use of contact testing in the characterization and design of all-ceramic crownlike layer structures: a review. J Prosthet Dent 2001; 86:495-510.

31-Lawn B, Lee S, et al. A model of strength degradation from hertzian contact damage in tough ceramics. J Amer Ceram Soc 1998; 81:1509-20.

32- Lawn BR, Deng Y, Lloyd IK, Janal MN, Rekow ED, Thompson VP. Materials design of ceramic-based layer structures for crowns. J Dent Res 2002; 81:433-8.

33-Lawn BR, Deng Y, et al. Overview: damage in brittle layer structures from concentrated loads. J Mater Res (in press).

34-Lawn BR, Wuttiphan S . Analysis of contact-induced transverse Fractures in brittle coatings on soft substrates. J Amer Ceram Soc (in press).

35-Malament K. Current analysis of clinical results. Dicor, InCeram and Empress. Boston, V. P. Thompson, 2003b.

36-Malament K , Thompson VP. Weibull analysis of a clinical data base of molar ceramic crowns [abstract n.231]. J Dent Res 2000; 79(Spec Issue).

37-Malament KA, Socransky S S. Survival of Dicor glass-ceramic dental restorations over 14 years: Part I. Survival of Dicor complete coverage restorations and effect of internal surface acid etching, tooth position, gender, and age. J Prosthet Dent 1999a; 81: 23-32.

38-Malament K A, Socransky SS. Survival of Dicor glass-ceramic dental restorations over 14 years. Part II: Effect of thickness of Dicor material and design of tooth preparation. J Prosthet Dent 1999b; 81:662-7.
39-Malament K A, Socransky S S. Survival of Dicor glass-ceramic dental restorations over 16 years. Part III: effect of luting agent and tooth or tooth-substitute core structure. J Prosthet Dent 2001;86: 511-9.

40-Malament KA, Socransky SS. Survival of glass-ceramic materials and involved clinical risk: variables affecting long-term survival. Pract Proced Aesthet Dent 2003a; Suppl: 5-11.

41-Mansour RM, Reynik RJ. In vivo occlusal forces and moments 1. Forces measured in terminal hinge position and associated moments. J Dent Res 1975; 54:114-20.

42-Marshall DB. Surface damage in ceramics: ilmplications for strength degradation, erosion and wear. Progress in Nitrogen Ceramics, Martinus Nijhoff, Boston, 1983.

43-Marshall DB, Lawn BR. Residual Stress Effects in SharpContact Cracking: I. Indentation Fracture Mechanics. J Mater Sci 1979;14:2001-12.

44-McLaren, E A, White, SN. Survival of in-ceram crowns in a private practice: a prospective clinical trial. J Prosthet Dent 2000 Feb; 83:216-22.

45- Oden A, Andersson M, Krystek-Ondracek I, Magnusson D. Five-year clinical evaluation of Procera AllCeram crowns. J Prosthet Dent 1998; 80:450-6.

46-Pajares A, Wei L, et al. Damage accumulation and cyclic fatigue in Mg-PSZ at hertzian contacts. J Mater Res 1995; 10:2613-25.

47-Pature N, Lawn L. Fatigue in ceramics with INterconnecting weak interface: a study using cyclic Hertzian contacts. Acta Metall Mat 1995;43:1609-17.

48- Peterson IM, Pajares A, Lawn BR, Thompson VP, Rekow ED. Mechanical characterization of dental ceramics by hertzian contacts. J Dent Res 1998b; 77:589-602.

49- Peterson IM, Wuttiphan S, Lawn BR, Chyung K . Role of microstructure on contact damage and strength degradation of micaceous glass-ceramics. Dent Mater 1998a; 14:80-9.

50-Scherrer SS, Rijk W G de.. The fracture resistance of all-ceramic crowns on supporting structures with different elastic module. Int J Prosthodont 1993; 6:462-7.

51- Scherrer SS, Rijk WG de, Belser UC, Meyer JM . Effect of cement thickness on the fracture resistance of a machinable glassceramic. Dent Mater 1994; 10:172-7.

52-Segal B S. Retrospective assessment of 546 all-ceramic anterior and posterior crowns in a general practice. J Prosthet Dent 2001; 85:544-50.

53-Sjogren G, Lantto R, et al. Clinical evaluation of all-ceramic crowns (Dicor) in general practice. J Prosthet Dent 1999; 81:27784.

54- Thompson JY, Anusavice KJ, Naman A, Morris HF. Fracture surface characterization of clinically failed all-ceramic crowns. J Dent Res 1994;73:1824-32. 
55- Tsai YL, Petsche PE, Anusavice KJ, Yang MC. Influence of glass-ceramic thickness on hertzian and bulk fracture mechanisms. Int J Prosthodont 1998; 11:27-32.

56-Wakabayashi N, Anusavice KJ. Crack initiation modes in bilayered alumina/porcelain disks as a function of core/veneer thickness ratio and supporting substrate stiffness. J Dent Res 2000;79:1398-404.

57- Wakasa K, Yamaki M, Matsui A.Calculation models for average stress and plastic deformation zone size of bonding area in dentine bonding systems. Dent Mater J 1995; 14:152-65.

58-Walton, TR. A 10-year longitudinal study of fixed prosthodontics: clinical characteristics and outcome of single-unit metal-ceramic crowns. Int J Prosthodont 1999;12:519-26.

59- Xu HH, Smith DT, Jahanmir S, Romberg E, Kelly JR, Thompson VP, Rekow ED. Indentation damage and mechanical properties of human enamel and dentin. J Dent Res 1998; 77:47280 .

Corresponding author: Van P. Thompson

New York University College of Dentistry

345 East $24^{\text {th }}$ Street

New York, NY 10010

Phone: 212998-9638

e-mail: van.thompson@nyu.edu 